\title{
Sensitivity of CryoSat-2 Arctic sea-ice freeboard and thickness on radar-waveform interpretation
}

\author{
R. Ricker ${ }^{1}$, S. Hendricks ${ }^{1}$, V. Helm ${ }^{1}$, H. Skourup ${ }^{2}$, and M. Davidson ${ }^{3}$ \\ ${ }^{1}$ Alfred Wegener Institute, Helmholtz Centre for Polar and Marine Research, Bremerhaven, Germany \\ ${ }^{2}$ DTU Space, Copenhagen, Denmark \\ ${ }^{3}$ ESA (ESTEC), Noordwijk, the Netherlands
}

Correspondence to: R. Ricker (robert.ricker@awi.de)

Received: 24 February 2014 - Published in The Cryosphere Discuss.: 2 April 2014

Revised: 10 July 2014 - Accepted: 16 July 2014 - Published: 28 August 2014

\begin{abstract}
In the context of quantifying Arctic ice-volume decrease at global scale, the CryoSat-2 satellite was launched in 2010 and is equipped with the $K_{\mathrm{u}}$ band synthetic aperture radar altimeter SIRAL (Synthetic Aperture Interferometric Radar Altimeter), which we use to derive sea-ice freeboard defined as the height of the ice surface above the sea level. Accurate CryoSat-2 range measurements over open water and the ice surface of the order of centimetres are necessary to achieve the required accuracy of the freeboardto-thickness conversion. Besides uncertainties of the actual sea-surface height and limited knowledge of ice and snow properties, the composition of radar backscatter and therefore the interpretation of radar echoes is crucial. This has consequences in the selection of retracker algorithms which are used to track the main scattering horizon and assign a range estimate to each CryoSat- 2 measurement. In this study we apply a retracker algorithm with thresholds of 40, 50 and $80 \%$ of the first maximum of radar echo power, spanning the range of values used in the current literature. By using the selected retrackers and additionally results from airborne validation measurements, we evaluate the uncertainties of sea-ice freeboard and higher-level products that arise from the choice of the retracker threshold only, independent of the uncertainties related to snow and ice properties. Our study shows that the choice of retracker thresholds does have a significant impact on magnitudes of estimates of sea-ice freeboard and thickness, but that the spatial distributions of these parameters are less affected. Specifically we find mean radar freeboard values of $0.121 \mathrm{~m}(0.265 \mathrm{~m})$ for the $40 \%$ threshold, $0.086 \mathrm{~m}(0.203 \mathrm{~m})$ for the $50 \%$ threshold and $0.024 \mathrm{~m}(0.092 \mathrm{~m})$ for the $80 \%$ threshold, considering
\end{abstract}

first-year ice (multiyear ice) in March 2013. We show that the main source of freeboard and thickness uncertainty results from the choice of the retracker and the unknown penetration of the radar pulse into the snow layer in conjunction with surface roughness effects. These uncertainties can cause a freeboard bias of roughly $0.06-0.12 \mathrm{~m}$. Furthermore we obtain a significant rise of $0.02-0.15 \mathrm{~m}$ of freeboard from March 2013 to November 2013 in the area for multiyear sea ice north of Greenland and Canada. Since this is unlikely, it gives rise to the assumption that applying different retracker thresholds depending on seasonal properties of the snow load is necessary in the future.

\section{Introduction}

Sea-ice thickness is an important parameter of the polar cryosphere, where changes in its seasonal cycle may cause significant negative feedbacks. There is already notable evidence of thinning of the Arctic sea ice (Rothrock et al., 1999). Together with the rapid reduction of ice-covered area (Comiso et al., 2008), especially during the summer season (Stroeve et al., 2012), the reduction of sea-ice volume in the Arctic might exceed the rate of ice extent decrease. Therefore, long-term observations of sea-ice thickness are required to assess current changes of Arctic sea-ice thickness and its implications for a further reduction of the ice cover.

Basin-scale measurements of sea-ice thickness are currently carried out by satellite altimeter missions. The altimetric sea-ice thickness retrieval is based on measurements of freeboard, the height of the ice surface above the local sea 
level, which can be used to calculate ice thickness (Kwok et al., 2009; Laxon et al., 2013). The radar altimeters onboard the European Remote Sensing (ERS) satellites (Laxon et al., 2003) are the first that were ever used for Arctic sea-ice thickness retrieval, followed by the Envisat mission. These pulselimited radar altimeters had a comparably large footprint between 2 and $10 \mathrm{~km}$ and a latitudinal limit of $81.5^{\circ} \mathrm{N}$ (Connor et al., 2009). A better coverage up to $86^{\circ} \mathrm{N}$ was possible with the ICESat (Ice, Cloud and land Elevation SATellite) mission, which featured a laser altimeter with a significantly smaller footprint $(70 \mathrm{~m})$, but could be affected by clouds. The current satellite altimeter dedicated to cryospheric science is CryoSat-2, a mission of the European Space Agency (ESA), which provides improved coverage of the Arctic up to $88^{\circ} \mathrm{N}$. It was launched in April 2010 and is equipped with a $K_{\mathrm{u}}$ band radar altimeter (SIRAL - Synthetic Aperture Interferometric Radar Altimeter). Its range retrieval enables the calculation of the sea-ice freeboard, which is the height of the ice surface above the actual sea level. The sea-ice freeboard can be converted into sea-ice thickness, assuming hydrostatic equilibrium (Laxon et al., 2003; Wadhams et al., 1992). Therefore it is crucial to measure the range to the main scattering horizon very accurately.

It has been suggested that $K_{\mathrm{u}}$ band radar waves do fully penetrate dry and cold snow (Beaven et al., 1995). However, field experiments indicate that snow moisture and density layering may prevent a radar from ranging through the snow to the ice surface in Arctic spring conditions over multiyear ice (MYI) (Willatt et al., 2011).

The range to the main scattering horizon is estimated at the leading edge of the radar echo waveforms (Tonboe et al., 2006). In synthetic aperture radar (SAR) altimetry, the waveform consists of a stack of collocated beams, separated from different bursts by their Doppler information. The range to the main scattering horizon is obtained by a retracker algorithm, either an empirical threshold of the peak power or an empirical approximation of the entire waveform. Theoretical considerations of SAR altimetry suggest that the main scattering horizon is located near the peak power and not at the half power point on the leading edge, as is the case for conventional pulse-limited altimeters (Wingham et al., 2004). However, a variety of assumptions are used in the literature. Laxon et al. (2013) used a leading-edge $50 \%$ threshold retracker, while in a recent study waveform fitting and the usage of a forward model result in an effective retracking near the waveform peak (Kurtz et al., 2014). In order to map land ice elevations, Helm et al. (2014) again focused on the lower part of the leading edge to minimize spatial and temporal variations of the volume scattering contribution. The location of the main scattering horizon below the snow surface depends significantly on the choice of the threshold or the empirical waveform fitting method. Kurtz et al. (2014) found a mean difference of $12 \mathrm{~cm}$ between a $50 \%$ threshold and a waveform fitting method with a near-peak threshold during the period 2011-2013. Therefore the choice of retracker adds to the existing uncertainty of physically limited penetration due to increased moisture, ice lenses in the snow layer or stratified high-density snow. In addition, uncertainties arise due to variable footprint-scale surface roughness and inaccurate reconstruction of the local sea-surface elevation.

The conversion of freeboard to sea-ice thickness again depends on the correct knowledge of snow depth and the densities of sea ice and snow, all parameters not very well constrained by observations at basin scale. First comparisons of CryoSat-2 sea-ice thickness data (Laxon et al., 2013) with validation data from airborne experiments and moorings show a good agreement on the large scale, but scatter in the data comparison reflects the residual uncertainties cited above. Quantifying these uncertainties is essential for trend estimates in sea ice and the use of CryoSat-2 data, for example in sea-ice modelling studies, especially for data assimilation.

Here, we present CryoSat-2 freeboard and thickness retrievals with consistent uncertainty estimates in spring/autumn 2013, using different approaches for waveform interpretation. We apply three different thresholds which span the range of values found in the literature and access their impact on CryoSat-2 Arctic sea-ice freeboard and thickness retrieval. The goal of our study is to isolate and quantify the effect of SAR waveform interpretation from other uncertainties that arise from the freeboard processing and the freeboard-to-thickness conversion. We describe the methodology and compare our findings to airborne data sets and other sea-ice remote sensing products. The contributions of different uncertainty sources are analysed for their impact on the freeboard and thickness retrieval relative to assumptions to the CryoSat-2 radar echo interpretation. We therefore investigate the effect of the retracker threshold range on the magnitude of Arctic sea-ice freeboard in spring and autumn.

\section{Data and methodology}

\subsection{Radar freeboard}

The term sea-ice freeboard usually refers to the elevation of the snow-ice interface above the local sea level. With different altimetry sensor wavelengths we define the terminology of freeboard (Fig. 1):

1. The ice freeboard refers to sea-ice freeboard as defined above. The lower wave propagation speed in the snow layer requires a correction based on assumed snow depth.

2. Snow freeboard: elevation of the air-snow interface, which is sensed by laser altimetry.

3. Radar freeboard: since the main scattering horizon may not coincide directly with the ice freeboard, we use the term radar freeboard for range measurements from 


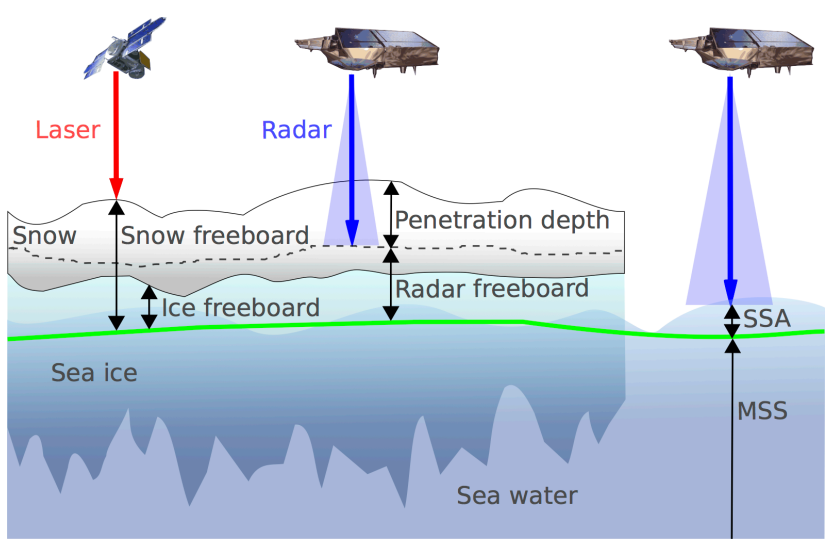

Figure 1. Schematic diagram of parameters regarding the CryoSat2 freeboard and thickness processing. The actual sea-surface height is composed of the mean sea-surface height (MSS) and the seasurface anomaly (SSA). The radar freeboard is obtained by subtracting the actual sea surface from the range retrieval over sea ice. In contrast to a laser altimeter (e.g. IceSat), the radar altimeter of CryoSat- 2 can penetrate the snow cover, depending on the snow properties.

CryoSat-2 (hereafter called CS-2). As for the ice freeboard the lower wave propagation speed in the snow layer requires a correction based on assumed snow depth and penetration, but is not applied for the radar freeboard in this study.

Figure 2 gives an outline of the steps in our data processing chain. To obtain radar freeboard it is necessary first to relate range estimates from the satellite to the main scattering surface. We use geolocated waveforms provided by ESA (L1b data set, baseline B) in both the SAR mode and the interferometric SAR (SARIn) mode which is applied in the western Arctic Ocean and coastal zones. SARIn data additionally contain phase information of the returning echo. Since they are not used in this study and to keep consistency, the phase information is discarded (Kurtz et al., 2014).

We obtain the two-way delay time of the averaged radar echoes (waveforms) by applying a TFMRA (threshold firstmaximum retracker algorithm) retracker (Helm et al., 2014). First, the original waveform is oversampled by a factor of 10 and a running mean with a width of 10 bins is applied to smooth the oversampled waveform (grey line in Fig. 3). The noise in front of the leading edge is suppressed with a power threshold. Then, the first local maximum is determined by the derivative of the curve. In the final step the leading edge of the first maximum of the waveform is tracked at a certain threshold of the maximum power of the waveform. We choose thresholds of $40 \%$ (TFMRA40), $50 \%$ (TFMRA50) and $80 \%$ (TFMRA80) of the first-maximum power to simulate the assumptions in Helm et al. (2014) and Laxon et al. (2013), and to emulate the waveform fitting method used in

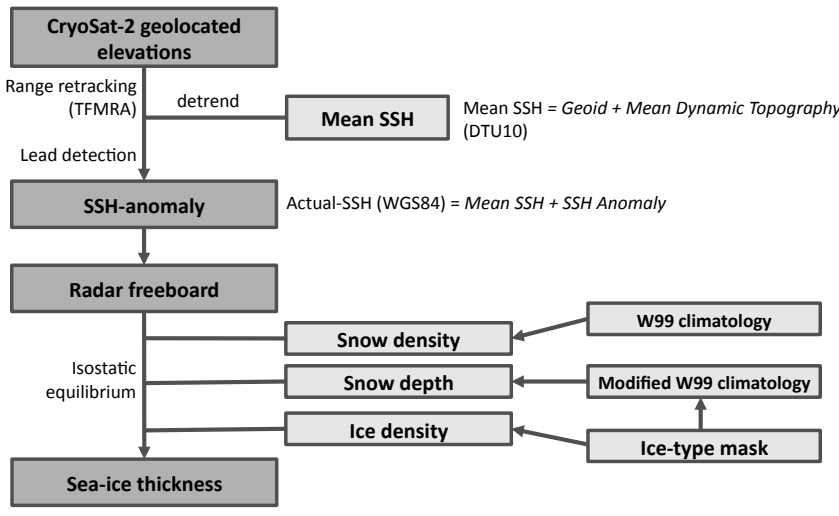

Figure 2. Flowchart of the CryoSat-2 data processing algorithm.

Kurtz et al. (2014) that tracks the leading edge rather close to the peak.

We assume that the resulting range gives the distance to the main scattering horizon at the individual threshold level. Figure 3 shows typical CS-2 waveforms for sea ice and leads and the different applied thresholds. As a result we receive geolocated ellipsoidal elevations of CS-2 data for each orbit over sea ice.

In the following step, the mean sea-surface (MSS) height product DTU10 (Andersen, 2010) is subtracted from the geolocated surface elevations to remove the main features of the actual sea-surface height. This is done to reduce errors in regions where the actual sea surface cannot be obtained with sufficient accuracy due to the absence of leads.

Then, by applying a lead detection algorithm, we automatically obtain the actual elevation of the sea level in ice-free sections of the CS-2 ground tracks. Leads between ice floes usually have far less surface waves than the open ocean and thus feature a distinct mirror-like peaky waveform. On the other hand, diffusive radar returns over snow-covered and roughened sea-ice surface lead to a wider angular distribution and a significantly different shape of the radar waveforms. Radar echoes over open ocean with higher significant wave height again show specific characteristics. In contrast to Laxon et al. (2013) we use the same retracker for both leads and sea ice to avoid biases due to the usage of different retracker algorithms.

This surface-type dependance of radar waveforms is traditionally used to automatically classify leads in the ice pack (Laxon, 1994; Drinkwater, 1991). We consider several waveform parameters that are either available in the raw data files or can be computed from the waveforms. Table 1 gives an overview of these parameters and their assumed threshold values which are used to distinguish between the surface types "ocean", "lead" and "sea ice". The surface type lead may not represent a single, large lead, but a sea-ice surface that typically includes a few small leads within the footprint. We use the "pulse peakiness" PP that has already been described in Giles et al. (2008) and Peacock and Laxon (2004). 
Table 1. Waveform parameters and ice concentration thresholds used in the CryoSat-2 processing algorithm to discriminate between the surface types "ocean", "lead" and "sea ice": pulse peakiness (PP), stack kurtosis $(K)$, standard deviation (SSD), peakiness left of the power maximum $\left(\mathrm{PP}_{1}\right)$, peakiness right of the power maximum $\left(\mathrm{PP}_{\mathrm{r}}\right)$, sea-ice concentration (IC) and the width of the OCOG box (OCOG WIDTH).

\begin{tabular}{llllllll}
\hline & \multicolumn{6}{c}{ Waveform parameter } \\
\cline { 2 - 7 } Type & $\mathrm{PP}$ & $K$ & $\mathrm{SSD}$ & $\mathrm{PP}_{1}$ & $\mathrm{PP}_{\mathrm{r}}$ & $\mathrm{IC}(\%)$ & OCOG WIDTH \\
\hline Ocean & $0 \leq \mathrm{PP} \leq 10$ & & $\geq 18.5$ & & & $\leq 5$ & $\geq 38$ \\
Lead & $\geq 40$ & $\geq 40$ & $\leq 4$ & $\geq 40$ & $\geq 30$ & $\geq 70$ & \\
Sea ice & & $\leq 8$ & & & $\leq 15$ & $\geq 70$ & \\
\hline
\end{tabular}
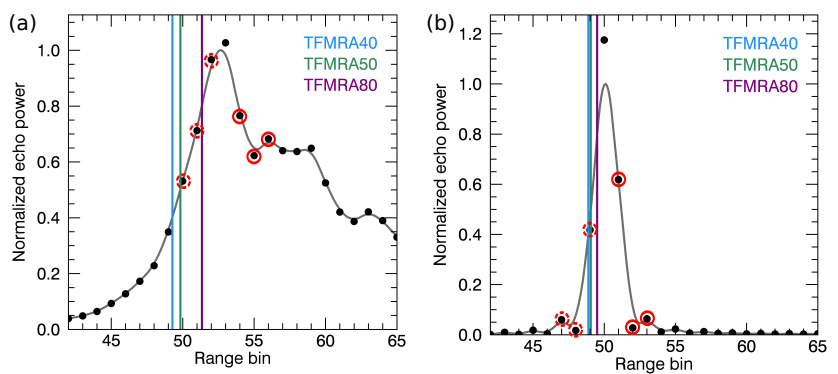

Figure 3. Typical CryoSat-2 waveforms for sea ice (a) and leads (b). The fitted waveform (grey) is a result of linear interpolation and smoothing of the original CryoSat-2 waveform (black dots). The coloured vertical lines represent the different applied TFMRA (threshold first-maximum retracker algorithm) thresholds in this study: $40 \%$ (TFMRA40), 50\% (TFMRA50) and $80 \%$ (TFMRA80). Red circles mark the range bins that are considered for the "left-hand" (dotted) and "right-hand" peakiness (solid).

It has to be noted that we used a slightly different notation of the pulse peakiness in contrast to Laxon et al. (2013):

$\mathrm{PP}=\sum_{i=1}^{N_{\mathrm{WF}}} \frac{\max (\mathrm{WF})}{\mathrm{WF}_{i}} \cdot N_{\mathrm{WF}}$.

Here $N_{\mathrm{WF}}$ represents the number of range bins and $\mathrm{WF}_{i}$ the echo power at range bin index $i$. Thus PP can be transferred to values in Laxon et al. (2013) by multiplication with a factor of $1 / N_{\mathrm{WF}}$. The second parameter is the "stack kurtosis" $(K)$, which is a measure of peakiness of range-integrated stack power distribution (Wingham et al., 2006). Here the term "stack" refers to an assembly of beam echoes which steer to a fixed point on the surface from different bursts. Specular reflections (narrow waveforms) from leads cause a high pulse peakiness as well as a small kurtosis. In contrast, echoes from sea ice are defined by waveforms with a wider power distribution and thus a lower peakiness. Further, the "stack standard deviation" (SSD) provides a measure of the variation in surface backscatter with incidence angle of the different beam echoes that are stacked (Wingham et al., 2006). Off-nadir reflections from leads can bias the range retrieval, since only a little area is required in the radar footprint to dominate the waveform (Armitage and Davidson, 2014).
Because those echoes do not show the typical specular reflection, they are discarded by introducing a modified pulse peakiness which considers only three range bins on the "left" $\left(\mathrm{PP}_{1}\right)$ and on the "right" $\left(\mathrm{PP}_{\mathrm{r}}\right)$ of the power maximum of a waveform 3:

$\mathrm{PP}_{\mathrm{r}}=\frac{\max (\mathrm{WF})}{\operatorname{mean}\left(\left[\mathrm{WF}_{i_{\max }-3}, \mathrm{WF}_{\left.\left.i_{\max }-1\right]\right)}\right.\right.} \cdot 3$,

$\mathrm{PP}_{1}=\frac{\max (\mathrm{WF})}{\operatorname{mean}\left(\left[\mathrm{WF}_{i_{\max }+1}, \mathrm{WF}_{\left.\left.i_{\max }+3\right]\right)}\right.\right.} \cdot 3$.

For the coarse discrimination between ocean and sea-ice area (including leads), we use interpolated ice concentration from the daily Ocean and Sea Ice Satellite Application Facility (OSI SAF) ice concentration product (Eastwood, 2012). To identify echoes from the ocean we additionally consider the "OCOG WIDTH", which is derived from the algorithm of the offset centre-of-gravity (OCOG) retracker (Wingham et al., 1986). It provides information about the "width" of the echo. Surface waves on the ocean cause a high OCOG WIDTH which can be used for the surface-type discrimination. Radar echoes that are not assigned to one of the surface types - ocean, lead or sea ice - are assumed to be biased by off-nadir leads and hence are discarded.

\subsubsection{Sea-surface anomaly}

The surface-type classification parameters were initialized based on manual tuning of example CS-2 ground tracks where coincident aircraft validation data (see Sect. 2.5) were available. We use a linear interpolation on the ranges of the retrieved open-water spots from leads. We then apply a running mean with $25 \mathrm{~km}$ width as a low-pass filter to smooth jumps that occur in dense lead clusters due to the signal noise. This procedure is done for each CS-2 track, yielding the sea-surface anomaly (SSA), the deviation of the actual sea-surface elevation from the mean sea-surface height (Fig. 1).

As the next step, the remaining anomaly from the mean sea-surface height (sea-surface anomaly), which is obtained by the interpolated lead elevations, is subtracted from the retracked surface elevations $L$, which were identified as sea 
ice in the surface-type discrimination. This is done for every single CS-2 track. The radar freeboard $\left(F_{\mathrm{R}}\right)$, which is not corrected for the lower wave propagation speed in the snow layer, is then obtained by

$F_{\mathrm{R}}=L-(\mathrm{MSS}+\mathrm{SSA})$.

We finally only allow freeboard values within the interval $-\sigma_{l 1 b}<F_{\mathrm{R}}<2 \mathrm{~m}+\sigma_{l 1 b}$, where $\sigma_{l 1 b}$ is the speckle noise (see Sect. 2.3) that represents random uncertainty of the range measurement and therefore should represent the lower boundary.

\subsection{Sea-ice thickness}

We consider the ice freeboard as a function of the radar freeboard $\left(F_{\mathrm{R}}\right)$, corrected by the penetration depth $\left(c_{\mathrm{p}}\right)$, a bias $\left(c_{\mathrm{r}}\right)$ due to surface roughness effects and $c_{\mathrm{W}}$, the correction for the lower wave propagation speed in the snow layer:

$F_{\mathrm{I}}=\alpha F_{\mathrm{R}}+c_{\mathrm{p}}+c_{\mathrm{r}}+c_{\mathrm{W}}$,

where $\alpha$ is a factor that represents the uncertainty due to the choice of the retracker threshold. Considering the fact that the values of $\alpha, c_{\mathrm{p}}, c_{\mathrm{r}}$ and $c_{\mathrm{W}}$ are uncertain, we do not apply correction terms in this study to get a consistent comparison. Therefore we assume that the uncorrected radar freeboard $F_{\mathrm{R}}$ represents the ice freeboard $F_{\mathrm{I}}$. Nevertheless correction terms have been applied for the AWI (Alfred Wegener Institute) CS-2 freeboard and thickness product (revision 1.0), which is available to the public (Hendricks et al., 2013).

The radar freeboard $\left(F_{\mathrm{R}}\right)$ can be converted into sea-ice thickness $T$ depending on the snow depth $(S)$ and the densities of snow $\left(\rho_{\mathrm{S}}\right)$, sea ice $\left(\rho_{\mathrm{I}}\right)$ and sea water $\left(\rho_{\mathrm{W}}\right)$ :

$T=F_{\mathrm{R}} \cdot \frac{\rho_{\mathrm{W}}}{\rho_{\mathrm{W}}-\rho_{\mathrm{I}}}+S \cdot \frac{\rho_{\mathrm{S}}}{\rho_{\mathrm{W}}-\rho_{\mathrm{I}}}$.

Corresponding to Laxon et al. (2013), we use the modified Warren snow climatology (W99) to estimate the snow depth (Warren et al., 1999) in the absence of year-round snow-depth observations for the entire Arctic Ocean. The climatology is based on observations from drift stations in a period where the Arctic Ocean was dominated by multiyear sea ice. It is therefore likely that the reduction of multiyear sea ice in the recent decade (Nghiem et al., 2007) may have impacted the distribution of snow depth in areas that are now more often covered by seasonal sea ice. Based on data from an airborne snow-depth radar, Kurtz and Farrell (2011) suggest that, though W99 is still representative for multiyear ice, snow depth has to be reduced in first-year ice (FYI) regions by $50 \%$. We follow this approach and classify the ice cover in first-year and multiyear sea ice using the daily icetype product from OSI SAF (Eastwood, 2012) and apply the snow-depth reduction accordingly. This step was introduced by Laxon et al. (2013) for CS-2 data processing. We additionally use the confidence level that is provided in the ice-type product to allow a mixture of both types at the boundaries.
The snow density $\left(\rho_{\mathrm{S}}\right)$ is adopted from the Warren snow water equivalent climatology (Warren et al., 1999). Both snow depths and snow density are available as a monthly product. Consistent with the approach of Laxon et al. (2013) we use ice densities $\left(\rho_{\mathrm{I}}\right)$ of $916.7 \mathrm{~kg} \mathrm{~m}^{3}$ for first-year ice (FYI) and $882.0 \mathrm{~kg} \mathrm{~m}^{3}$ for MYI (Alexandrov et al., 2010). Furthermore we assume a value of $1024 \mathrm{~kg} \mathrm{~m}^{3}$ for the water density $\left(\rho_{\mathrm{W}}\right)$.

The freeboard-to-thickness conversion is applied for each individual CS-2 ground track. We calculate ice thickness from an individual data point and not from a larger-scale averaged snow freeboard in order to allow estimation of individual uncertainties of retrieved thickness after later spatial downsampling.

\subsection{Uncertainty of freeboard and thickness}

We consider two sources of uncertainties:

1. Random uncertainties that originate from random fluctuations during the measurement and usually can be minimized by increasing the number of measurements.

2. A bias or systematic uncertainty has a assignable cause and the same magnitude for all measurements and thus cannot be reduced by averaging.

In Wingham et al. (2006) different types of errors from CS-2 measurements over sea ice have already been discussed. The first of which are errors that affect the range measurements, e.g. speckle noise. Second, the uncertainty of the actual sea-level height (MSS + SSA), which affects the freeboard retrieval through Eq. (4). Third, there is uncertainty as to the location of the reflection horizon depending on the physical properties of the snow cover. It can be combined with the uncertainty of the choice of the retracker threshold. Furthermore there are contributions which arise from uncertainties in densities of the sea-ice layer and snow loading, directly affecting the thickness retrieval through Eq. (6). Finally Wingham et al. (2006) considered potential high-level errors due to limited recording of thin ice $(<1 \mathrm{~m})$. However this was observed for pulse-limited radar altimetry and is still not clarified for CS-2 (Laxon et al., 2013).

Figure 4 provides an overview of all individual uncertainties that are incorporated into the freeboard and thickness uncertainty budget in this study. We acknowledge that this is only an approximation resulting from incomplete knowledge of the covariance of individual error contributions.

The random uncertainty of radar freeboard is assumed to be governed by the speckle noise and the accuracy of the actual sea-surface height. The latter depends on the abundance of detected leads, which are needed for an accurate interpolation of the sea-surface anomaly. These two uncertainties are considered to be uncorrelated.

According to Wingham et al. (2006), the speckle noise that originates from instrument system errors is assumed to be 


\section{Freeboard uncertainties}

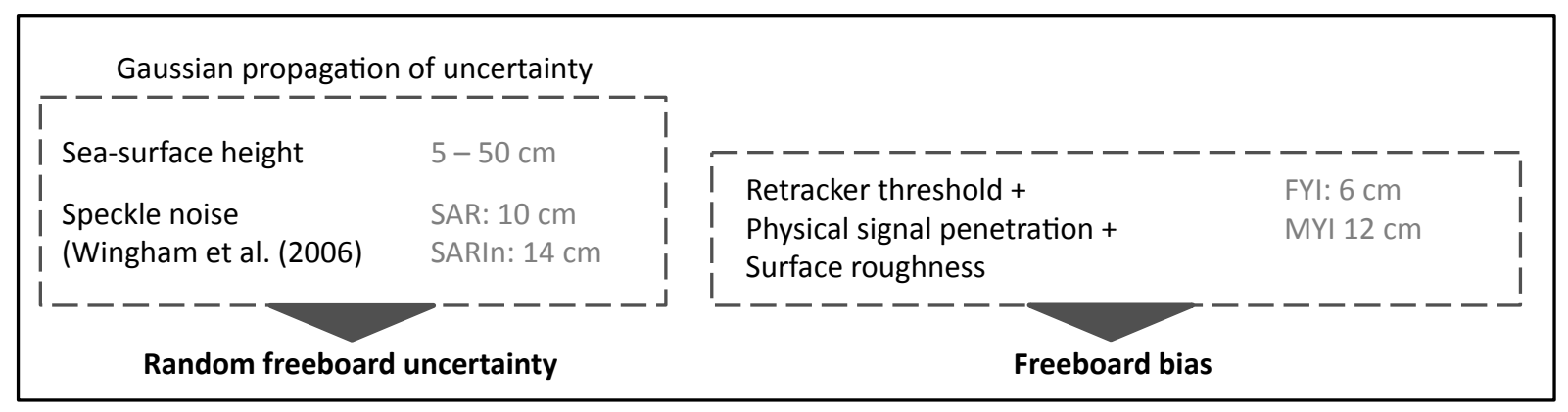

Thickness uncertainties

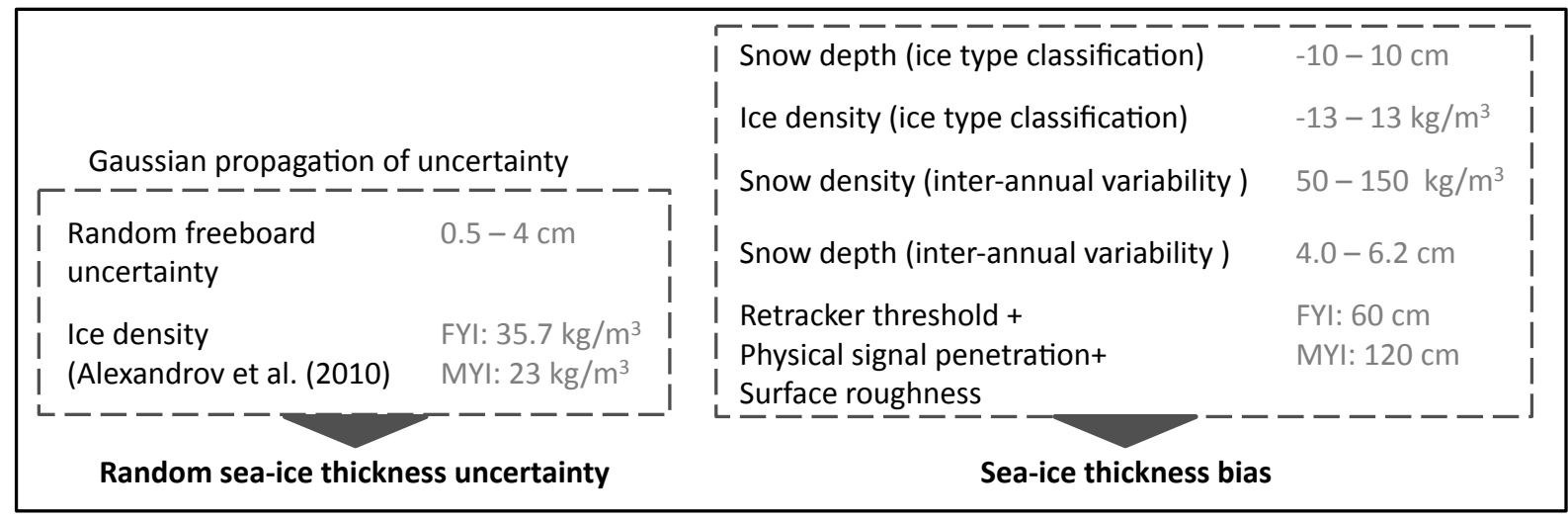

Figure 4. Flowchart of the CryoSat-2 uncertainty budget for freeboard and thickness, showing the typical range for the individual uncertainty of each parameter and referring to a single CryoSat-2 measurement.

$\sigma_{l 1 b}=0.10 \mathrm{~m}$ for SAR mode and $\sigma_{l 1 b}=0.14 \mathrm{~m}$ for SARIn mode. It affects the lead elevations as well as the ice floe elevations. The lead coverage is variable, depending on season, region and ice type. The SSA uncertainty $\left(\sigma_{\mathrm{SSA}}\right)$ is computed by taking the standard deviation of the detected lead elevations within a moving $25 \mathrm{~km}$ window. In the absence of leads inside the moving window the uncertainty is given by the deviation of the interpolated SSA from the mean CS-2 elevation. As a consequence it rises with decreasing density of detected leads along a CS-2 ground track. We can then estimate the uncertainty of an individual radar freeboard measurement by adding the variances (Fig. 4):

$\sigma_{F_{\mathrm{R}}}^{2}=\sigma_{l 1 b}^{2}+\sigma_{\mathrm{SSA}}^{2}$.

The choice of the retracker threshold in conjunction with the incomplete knowledge about the penetration of the radar pulse and the effect of surface roughness causes a bias which affects all measurements in the same way. We quantify this bias by comparing the results of using different retracker thresholds.

For the sea-ice thickness uncertainty we again separate between random uncertainties and biases (Fig. 4). The random uncertainties are assumed to be uncorrelated an can be combined via Gaussian propagation of uncertainty. For both types of uncertainties we have to calculate the partial derivatives of
Eq. (6) as weights for the variances of the single variables to get the contribution to the thickness uncertainty:

$$
\begin{aligned}
\frac{\partial T}{\partial F_{\mathrm{R}}} & =\frac{\rho_{\mathrm{W}}}{\rho_{\mathrm{W}}-\rho_{\mathrm{I}}} \\
\frac{\partial T}{\partial \rho_{\mathrm{S}}} & =\frac{S}{\rho_{\mathrm{W}}-\rho_{\mathrm{I}}} \\
\frac{\partial T}{\partial \rho_{\mathrm{I}}} & =\frac{F_{\mathrm{R}} \cdot \rho_{\mathrm{W}}+S \cdot \rho_{\mathrm{S}}}{\left(\rho_{\mathrm{W}}-\rho_{\mathrm{I}}\right)^{2}} \\
\frac{\partial T}{\partial S} & =\frac{\rho_{S}}{\rho_{\mathrm{W}}-\rho_{\mathrm{I}}} .
\end{aligned}
$$

The random thickness uncertainty of an individual measurement can then be determined by

$$
\sigma_{T}^{2}=\left(\frac{\partial T}{\partial F_{\mathrm{R}}} \cdot \sigma_{F_{\mathrm{R}}}\right)^{2}+\left(\frac{\partial T}{\partial \rho_{\mathrm{I}}} \cdot \sigma_{\rho_{\mathrm{I}}}\right)^{2}
$$

using the result for the random uncertainty $\left(\sigma_{F_{\mathrm{R}}}\right)$ of radar freeboard (Eq. 7) and the uncertainty of ice density $\left(\sigma_{\rho_{\mathrm{I}}}\right)$ that is adopted from Alexandrov et al. (2010) and is assumed to be $35.7 \mathrm{~kg} \mathrm{~m}^{3}$ for FYI and $23.0 \mathrm{~kg} \mathrm{~m}^{3}$ for MYI. The contribution of uncertainties due to the variability of water density is neglected (Kurtz et al., 2012).

Further uncertainties concerning the thickness retrieval are considered as biases and do not decrease due to averaging. 
As for the freeboard, the choice of the retracker threshold in conjunction with the incomplete knowledge about the penetration of the radar pulse and the effect of surface roughness also affects the thickness retrieval. Furthermore the uncertainties of the modified W99 snow depth and snow density due to interannual variabilities are assumed to be systematic and cannot be treated as random uncertainties. Therefore we use the interannual variability of snow depth and snow water equivalent, provided in Warren et al. (1999), to access this potential bias. The OSI SAF ice-type product is applied to form the modified W99 snow depth and the ice density field. The ice-type product is provided with a confidence level that is used as a measure of uncertainty. A wrong ice-type classification biases both the snow depth and the ice density.

Each of the systematic uncertainties is multiplied with the partial derivative of the respective variable (Eq. 8) to obtain the contribution to the thickness uncertainty.

\subsection{Gridding}

Including radar freeboard, snow depth, sea-ice thickness and all auxiliary data products, data for 1 month are averaged on the EASE-Grid 2.0 (Brodzik et al., 2012) with a resolution of $25 \mathrm{~km}$. For averaging radar freeboard and thickness we use the weighted arithmetic mean, which is calculated from all processed data points within the boundaries of a grid cell. As weights we use the squares of the individual random uncertainties. For mean radar freeboard $\left(\bar{F}_{\mathrm{R}}\right)$ and mean sea-ice thickness $(\bar{T})$, each grid cell represents the mean value of data points classified as sea ice only, without the open-water fraction:

$$
\bar{F}_{\mathrm{R}}, \bar{T}=\frac{\sum_{i=1}^{N} \frac{1}{\sigma_{\left[F_{\mathrm{R}_{i}}, T_{i}\right]}} \cdot\left[F_{\mathrm{R}_{i}}, T_{i}\right]}{\sum_{i=1}^{N} \frac{1}{\sigma_{\left[F_{\mathrm{R}_{i}}, T_{i}\right]}^{2}}},
$$

where $N$ is the number of CS-2 freeboard and thickness measurements inside a grid cell. Due to monthly averaging the random uncertainties of the individual measurements decrease with $\sqrt{N}$, leading to the random freeboard and thickness uncertainties of a grid cell:

$\sigma_{\bar{F}_{\mathrm{R}}, \bar{T}}=\sqrt{\frac{1}{\sum_{i=1}^{N} \frac{1}{\sigma_{\left[F_{R_{i}}, T_{i}\right]}}}}$.

Since the W99 climatology is based upon in situ measurements (Warren et al., 1999), regions without sampling or with insufficient sampling should be excluded. Therefore we provide a sea-ice mask but exclude certain regions, e.g. Baffin Bay, the Canadian Arctic Archipelago and the region between Greenland and Severnaya Zemlya below $80^{\circ} \mathrm{N}$ (Fig. 5a). Figure 5b shows the data mask and an example of a monthly average snow-depth field from March 2011.
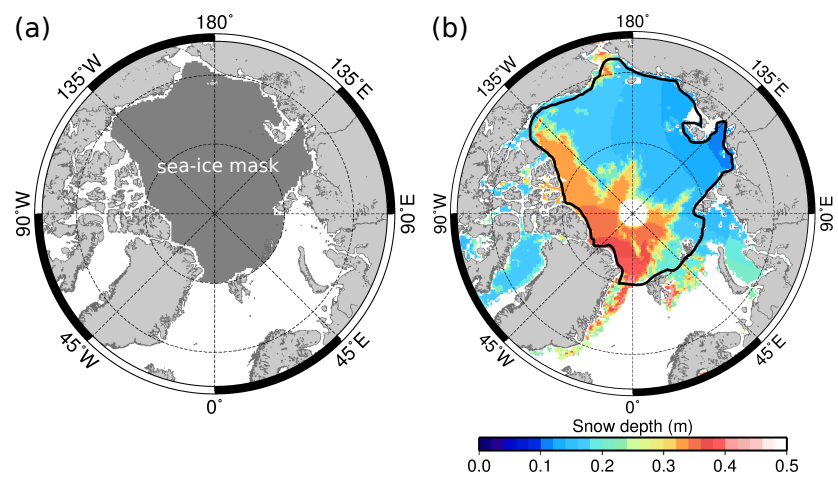

Figure 5. (a) Data mask, which is applied to calculate sea-ice thickness estimates. Only thickness data within the dark grey area are considered as valid. (b) Snow depth from March 2011 and data mask (solid black line). Thickness data in excluded regions are discarded because the W99 snow-depth fit is not valid there.

\subsection{Airborne data}

The penetration of the radar pulse, the effect of surface roughness as well as the choice of the retracking point are still under investigation. Laser altimetry is a valuable technique for their evaluation because it is always referring to the snow freeboard (Fig. 1).

Since 2003 the CryoSat Validation Experiment (CryoVex) has been carried out over sea ice in the Northern Hemisphere to directly validate CS-2 products. During the CryoVEx campaign in the Lincoln Sea in spring 2011 the first coincident measurements by CS- 2 and two research aircraft were accomplished. Besides other sensors a laser scanner was mounted onboard the AWI aircraft "Polar 5".

Airborne laser scanners (ALSs) provide high-precision and high-resolution measurements and thus are capable of evaluating measurements of the radar altimeter SIRAL on CryoSat-2. The accuracy for the range measurements is about a few centimetres. The main limitation is due to GPS positioning, especially for a longer baseline of more than $100 \mathrm{~km}$ (Forsberg et al., 2002).

The laser scanner has been operated at an altitude of $300 \mathrm{~m}$ with around 370 shot points per scan line and a point spacing of around $0.3 \mathrm{~m}$. The spacing along track has been around $1 \mathrm{~m}$. We include two flights in our analysis where we consider profile sections with a total length of about $450 \mathrm{~km}$ in coincidence with CS-2. They were conducted over the Lincoln Sea on 15 and 17 April, operated from the Canadian Forces Station Alert (Fig. 6a and Fig. 7a).

Consistent with the CS-2 processing, the geolocated ALS elevations have to be referenced to the actual sea-surface height. Therefore leads are picked manually from the ALS elevation model. The sea-surface height is then determined along the centre shot points by applying a spline interpolation. The snow freeboard is obtained by subtracting the seasurface height from the geolocated ALS elevations. 


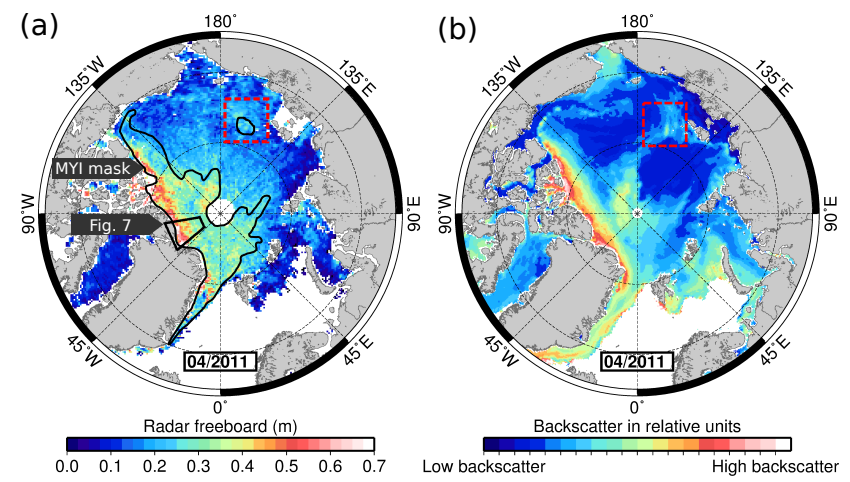

Figure 6. (a) CryoSat-2 mean radar freeboard of April 2011, retrieved by applying the TFMRA40 retracker. It shows the area of coincident validation flights in April 2011 (black box; see Fig. 7). (b) METOP ASCAT mean backscatter for April 2011. The red dashed box marks a common feature of (a) and (b).

In the following step ALS data are averaged over the respective CS-2 Doppler cell, which is assumed to cover an area of $300 \mathrm{~m}$ by $1000 \mathrm{~m}$. In order to provide a consistent comparison with CS-2 measurements, the ALS data points are weighted, depending on the distance to the respective CS-2 data point, which we assume to be located in the centre of the CS-2 Doppler cell. The averaging process is applied to accommodate the footprint geometry and therefore the coarser-resolution CS-2 measurements. Finally every averaged value of the ALS data is assigned to a corresponding CS-2 data point.

\section{Results}

In this section we first describe the results from the CS-2 freeboard processing. Then we consider results of the performance of different CS-2 retracker thresholds and their differences, also using airborne laser altimetry as a reference. Finally contributions of uncertainties in the waveform interpretation are considered in the context of additional random and systematic uncertainties.

\subsection{Radar freeboard retrieval}

Figure 6a shows the CS-2 mean radar freeboard retrieval from April 2011 using the TFMRA40 retracker. We find a mean radar freeboard of $0.3 \mathrm{~m}$ in the MYI region north of Greenland and Canada and a mean radar freeboard of $0.16 \mathrm{~m}$ for FYI. For the discrimination between FYI and MYI we use a monthly mean ice-type product. This originates from the CS-2 data processing where OSI SAF ice-type data are interpolated along each CS-2 ground track. As for the CS2 freeboard and thickness retrieval, the interpolated ice-type data are averaged on the EASE-Grid 2.0 over 1 month.

Figure $6 \mathrm{~b}$ shows a monthly mean of backscatter from April 2011, obtained from the Advanced Scatterometer (AS-
CAT) onboard the Meteorological Operational Satellite. The backscatter is affected by the dielectric properties of the snow and the surface roughness that both change with the ice type. High backscatter indicates a rather rough surface and is usually associated with MYI, whereas low backscatter rather indicates younger FYI. A slightly increased freeboard can be observed in the East Siberian Sea. It occurs as higher backscatter (red dashed square). Together with Special Sensor Microwave Imager (SSM/I) passive microwave radiometer, MESOP ASCAT backscatter is also an input for the OSI SAF ice-type classification that is used to build the modified W99 snow depth as well as the ice density field.

\subsection{Comparison with airborne laser altimetry (ALS)}

Figures 7 and 8 show ALS snow freeboard and uncorrected CS-2 radar freeboard $F_{\mathrm{R}}$ for different retracker thresholds. Gaps in Fig. 7b originate from discarded CS-2 data that were biased by off-nadir leads, insufficient retracking or poor quality in the ALS data. We additionally smoothed all data sets with a running mean of $10 \mathrm{~km}$ width to reduce noise and small-scale artefacts. The along-track comparison in Fig. $7 \mathrm{~b}$ shows some long-scale agreement of the freeboard gradient, particularly between 150 and $200 \mathrm{~km}$ track distance on ground track 5428. This applies to all of the three threshold retrievals. Nevertheless the magnitude of variations in the ALS retrieval is higher than in the CS-2 freeboard.

The TFMRA40 freeboard is the closest to the snow freeboard. The mean difference to the snow surface is $0.21 \mathrm{~m}$. The TFMRA50 freeboard is $0.1 \mathrm{~m}$ below the TFMRA40 freeboard on average. Both show very similar magnitudes of variations. This is also shown in the corresponding probability density functions in Fig. 8. Here we use a relative probability that reveals the modal freeboard as the peak of the function which represents the level ice. The tail represents the fraction of deformed ice.

In contrast to the 40 and $50 \%$ threshold retrievals, the TFMRA 80 is very close to the sea level and deviates by a mean distance of $0.52 \mathrm{~m}$ to the snow freeboard. It also shows less variation in magnitude, resulting in a narrow distribution (Fig. 8).

\subsection{Freeboard and thickness from different retracker thresholds and uncertainties}

Figure 9 shows the uncorrected radar freeboard from March and November 2013 for each threshold. Similar to Fig. 6 we find a significant increase of freeboard for the MYI north of Greenland and Canada of up to $0.55 \mathrm{~m}(40 \%), 0.45 \mathrm{~m}(50 \%)$ and $0.3 \mathrm{~m}(80 \%)$, whereas FYI regions (e.g. East Siberian Sea) are characterized by a lower radar freeboard, especially in November. The patterns are similar for all applied thresholds, but with different magnitudes.

Figure 10 shows the random uncertainties corresponding to Fig. 9. They result from Eqs. (7) and (11) and show a 
(a)

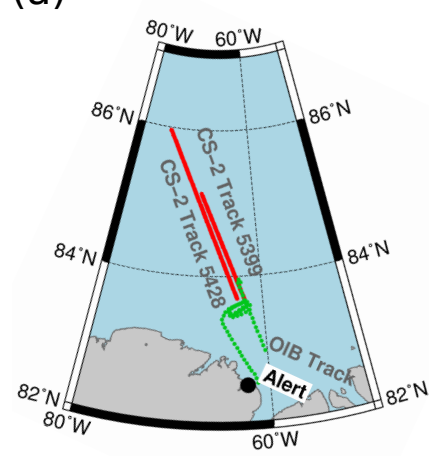

(b)
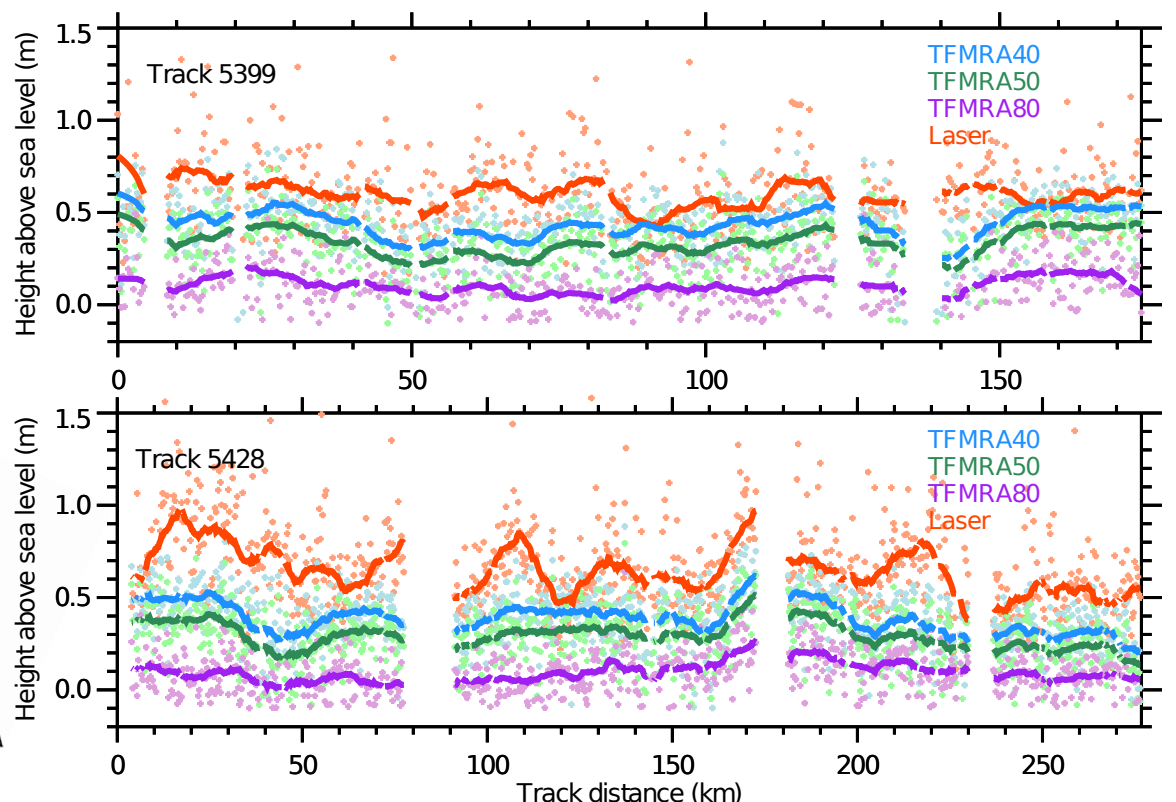

Figure 7. (a) Area of coincident flights of CryoSat-2 (CS-2) and Polar-5 (black box in Fig. 6) from 15 and 17 April 2011. The green dotted line shows the track of Operation IceBridge (OIB) flight 1038 that carried a snow-depth radar. The aircraft surveyed the ascending CryoSat- 2 tracks from the southeast to the northwest. (b) Uncorrected TFMRA40, TFMRA50 and TFMRA80 radar freeboard of CryoSat-2 and snow freeboard from airborne laser altimetry ("Laser") along CryoSat-2 tracks 5399 and 5428. For the comparison only valid data from coincident coverage are considered. The dots represent the original data with a spatial resolution of $300 \mathrm{~m}$. We additionally applied a running mean (10 km width, solid lines).
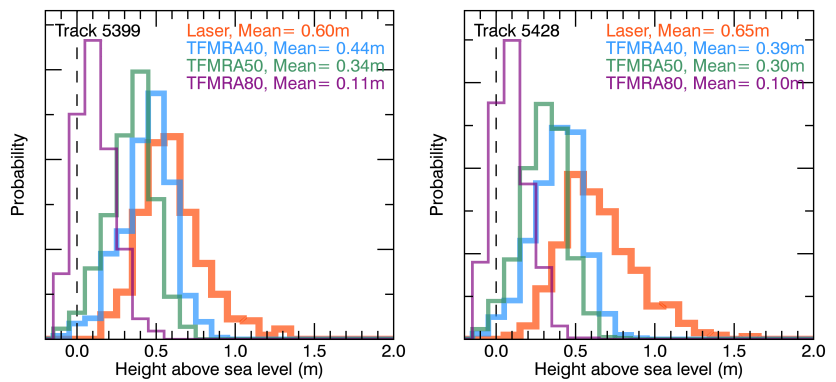

Figure 8. Probability density functions corresponding to Fig. $7 \mathrm{~b}$. For the comparison only valid data from coincident coverage are considered.

latitude-dependent gradient. The mean uncertainties for FYI and MYI do not differ significantly and are between 0.01 and $0.04 \mathrm{~m}$ except for the ice edge and land-fast ice regions (e.g. Laptev Sea), where they can reach $0.07 \mathrm{~m}$. Magnitude and pattern of the random freeboard uncertainties are very similar for all applied thresholds.

Table 2 summarizes the corresponding mean values classified into FYI and MYI for the use of different thresholds. Considering the results of the TFMRA40 retracker, we find a mean radar freeboard of $0.12 \mathrm{~m}(0.25 \mathrm{~m})$ for FYI (MYI) in March and $0.08 \mathrm{~m}(0.26 \mathrm{~m})$ for FYI (MYI) in November. In comparison to the TFMRA40, the TFMRA50 mean radar freeboard is decreased by $0.04 \mathrm{~m}(0.06 \mathrm{~m})$ for FYI (MYI) in
Table 2. Mean radar freeboard $F_{\mathrm{R}}$ of gridded data for March and November 2013, discriminated between first-year ice (FYI) and multiyear ice (MYI).

\begin{tabular}{lrrrr}
\hline & \multicolumn{2}{c}{ March 2013 } & \multicolumn{2}{c}{ November 2013 } \\
\hline & FYI (m) & MYI (m) & FYI(m) & MYI (m) \\
TFMRA40 & 0.121 & 0.247 & 0.077 & 0.257 \\
TFMRA50 & 0.086 & 0.187 & 0.048 & 0.190 \\
TFMRA80 & 0.025 & 0.076 & -0.004 & 0.065 \\
\hline
\end{tabular}

March 2013 and $0.03 \mathrm{~m}(0.07 \mathrm{~m})$ for FYI (MYI) in November 2013. Considering the TFMRA80 mean radar freeboard, we find a significant decrease in comparison to the retrievals from using the other thresholds. The TFMRA80 mean radar freeboard is decreased by $0.10 \mathrm{~m}(0.17 \mathrm{~m})$ for FYI (MYI) in March and $0.08 \mathrm{~m}(0.19 \mathrm{~m})$ for FYI (MYI) in November compared to the TFMRA40 retrieval. Furthermore the mean radar freeboard for FYI of November 2013 shows a value which is negative and close to the sea level.

Figure 11 shows the spatial differences between the freeboard retrievals from using 40, 50 and $80 \%$ thresholds. Consistent with the mean differences in Table 2, we find only small differences in the range of $0.05 \mathrm{~m}$ for FYI and up to $0.1 \mathrm{~m}$ for MYI between the 40 and the $50 \%$ threshold retrievals. Nevertheless the MYI pattern is slightly visible (Fig. 11a). In contrast the difference magnitudes between the 

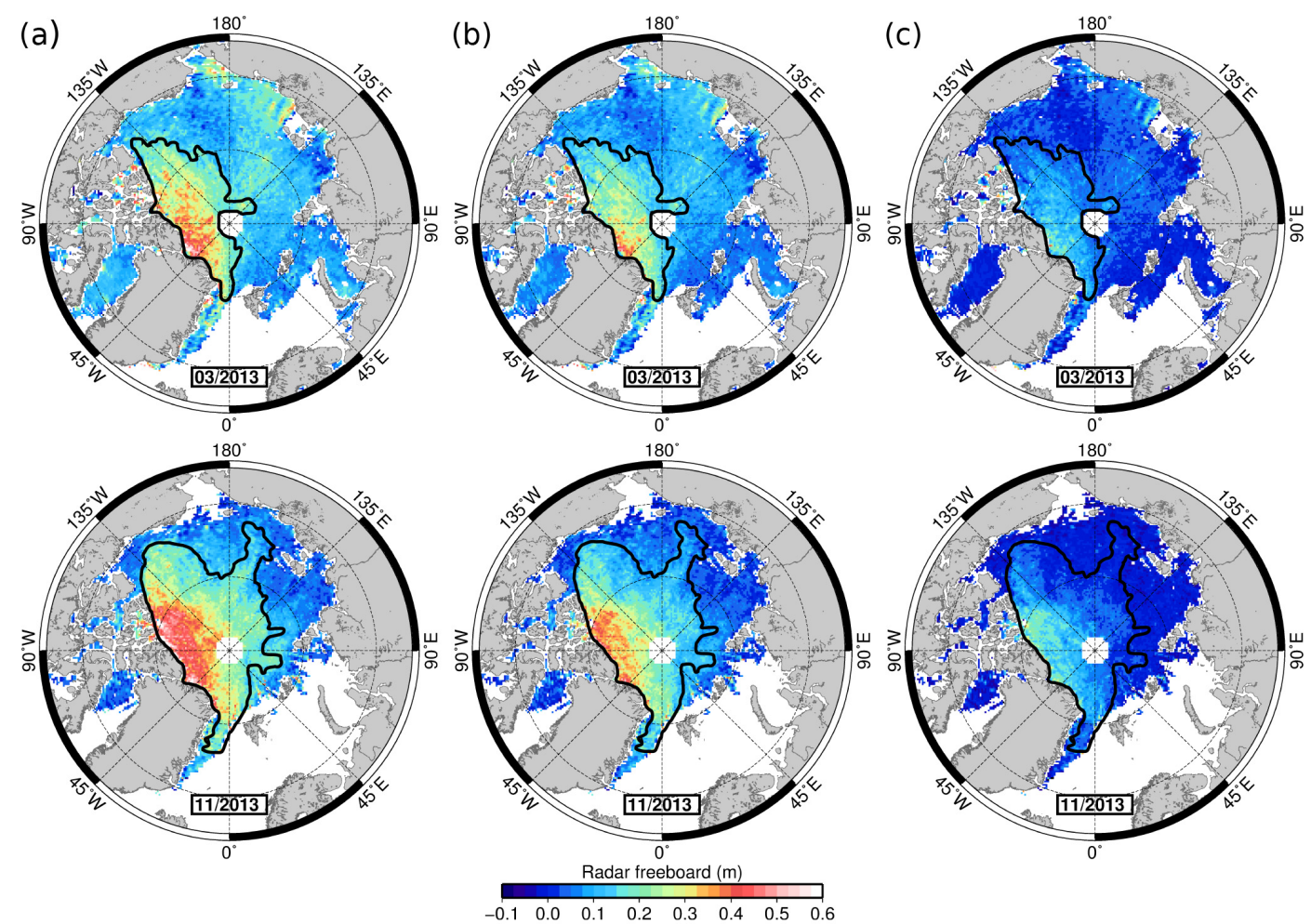

Figure 9. Radar freeboard from different TFMRA (threshold first-maximum retracker algorithm) retracker thresholds for March (upper row) and November (lower row) 2013: (a) $40 \%$, (b) $50 \%$ and (c) $80 \%$ threshold. The black polygon defines the averaged MYI zone, retrieved from the OSI SAF ice-type product.
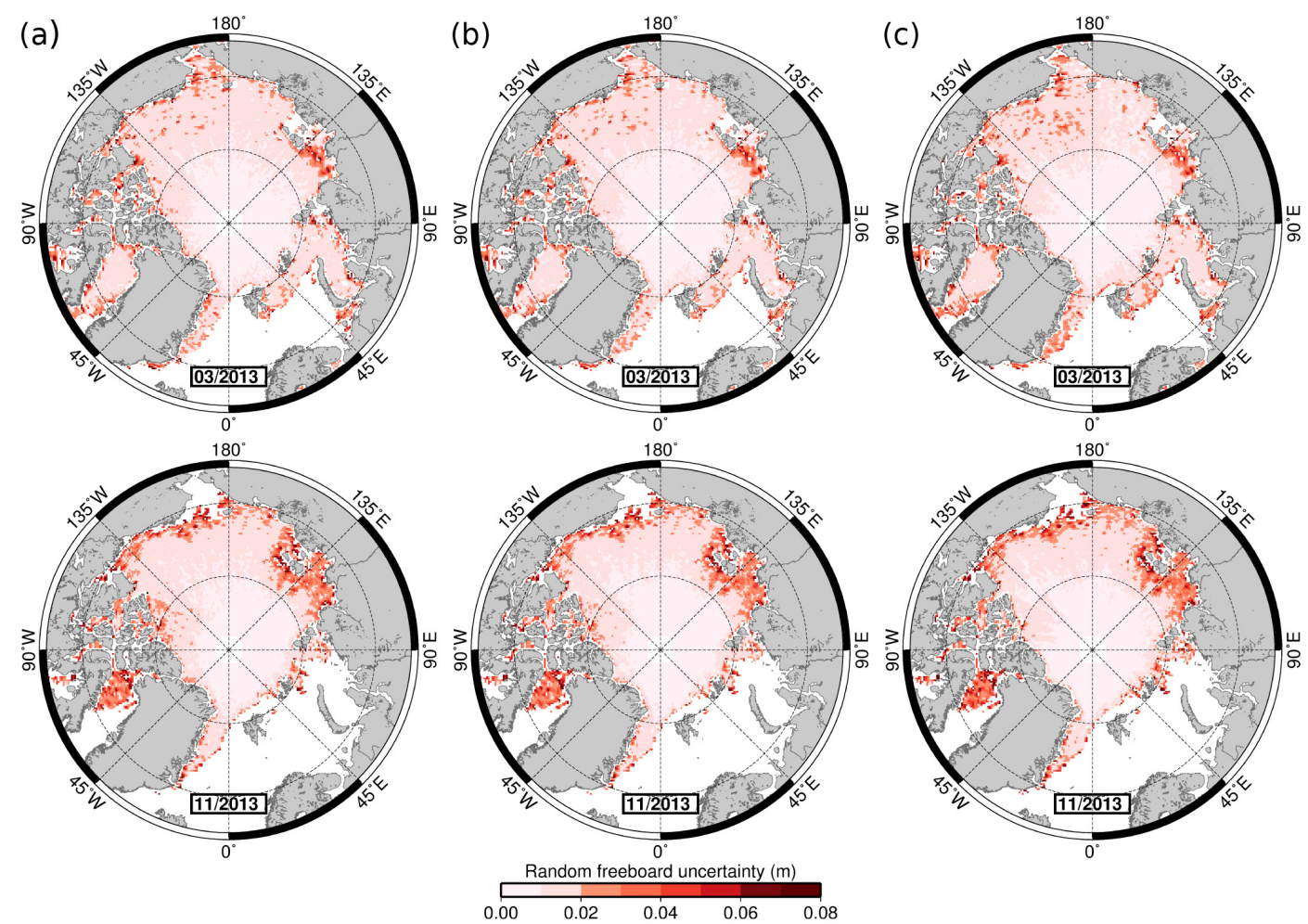

Figure 10. Random freeboard uncertainties corresponding to Fig. 9: (a) TFMRA40, (b) TFMRA50 and (c) TFMRA80. The uncertainties result from Gaussian propagation of uncertainty (Fig. 4). 


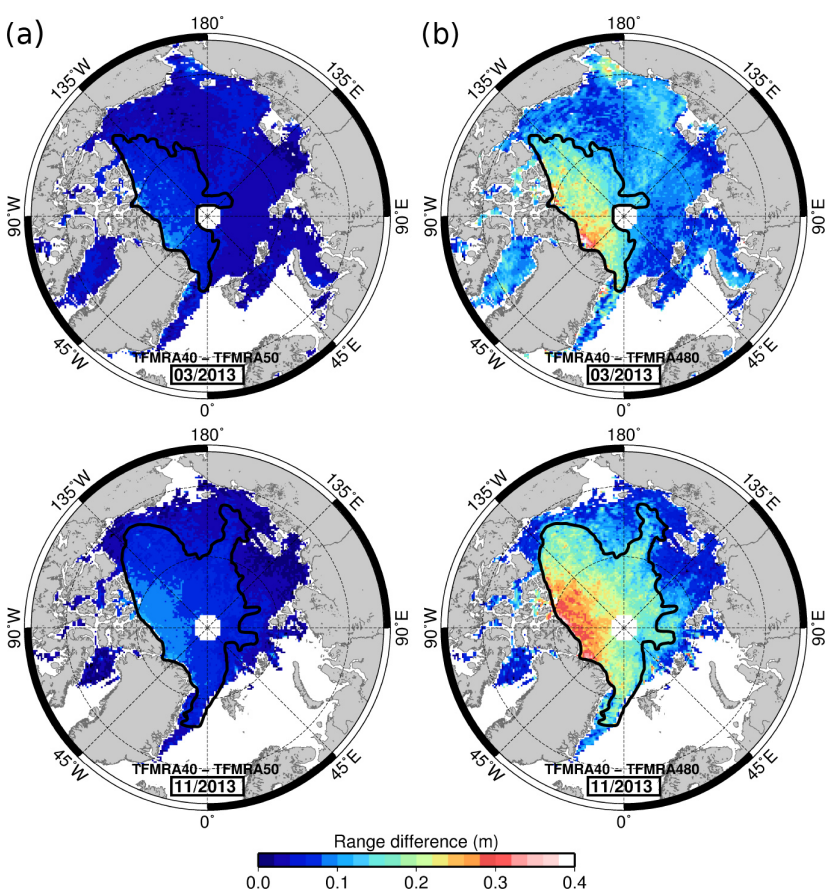

Figure 11. Range differences between different TFMRA (threshold first-maximum retracker algorithm) retracker thresholds for March (upper row) and November (lower row) 2013. (a) TFMRA40TFMRA50, (b) TFMRA40-TFMRA80. The black polygon defines the averaged MYI zone, retrieved from the OSI SAF ice-type product.

$40 \%$ threshold and the $80 \%$ threshold are higher and reach $0.15 \mathrm{~m}$ for FYI and $0.3 \mathrm{~m}$ for MYI (Fig. 11b). Besides the ice-type pattern there is also a visible gradient within the MYI, showing higher differences north of Greenland of up to $0.35 \mathrm{~m}$.

Figure 12a shows the sea-ice thickness estimate from March and November 2013 together with the corresponding uncertainty maps (Fig. 12b), using the $50 \%$ threshold. Areas where the W99 climatology is not valid have been excluded (Fig. 5). The spatial distribution is similar to the radar freeboard retrieval and results from Eq. (6), without using a correction term for the signal penetration into snow. The random thickness uncertainties are increased by a factor of around 10 and also feature the same pattern as the random freeboard uncertainties in Fig. 10.

Figure 13 shows contributions to the systematic sea-ice thickness uncertainty for March 2013. The bias uncertainty of each parameter (e.g. snow depth, ice and snow density) is multiplied with the corresponding partial derivative (Eq. 8) and hence gives the contribution to the thickness bias. Figure 13a shows the bias that results from the interannual snowdepth variability. Here we find values between $0.12 \mathrm{~m}$ (FYI) and $0.21 \mathrm{~m}$ (MYI) for March 2013. Figure 13b shows the bias resulting from the interannual snow-density variability. It is between $0.10 \mathrm{~m}$ (FYI) and $0.18 \mathrm{~m}$ (MYI). In contrast to (a)

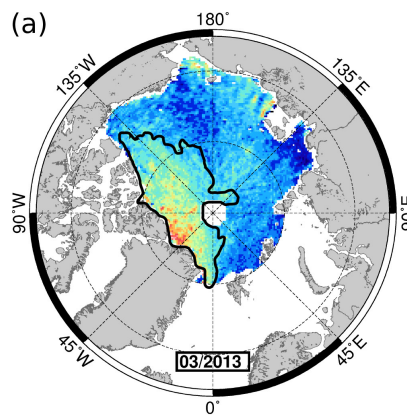

(b)
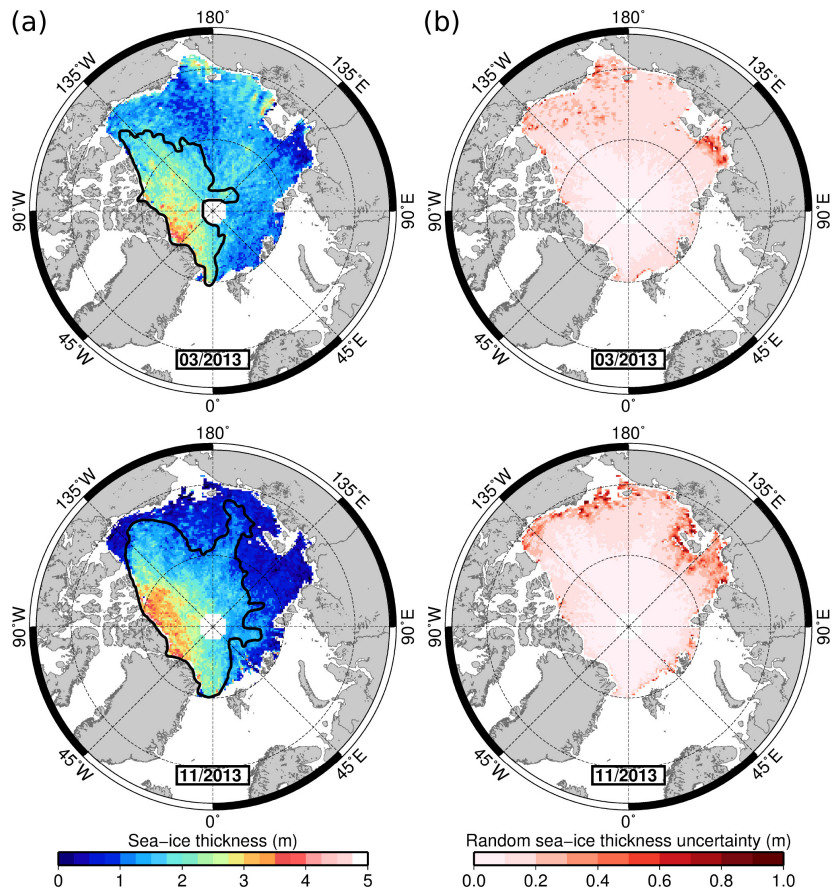

Figure 12. (a) CryoSat-2 Arctic sea-ice thickness from March and November 2013, applying the $50 \%$ threshold. (b) Random thickness uncertainties corresponding to (a). The black polygon defines the averaged MYI zone, retrieved from the OSI SAF ice-type product.

Fig. 13a we find an inverse pattern for the ice-type dependency. Figure 13c shows the thickness bias that originates from the ice-type classification which is used to construct the snow-depth field. In contrast to Fig. 13a and b the bias features positive and negative values with peaks at the boundary between FYI and MYI where the uncertainty of the ice-type classification is relatively high. There we find values of up to $\pm 0.05 \mathrm{~m}$ for March 2013. The same pattern, just inverse, is shown by the ice-density bias, which is induced due to the ice-type classification (Fig. 13d). Here we find values of $\pm 0.04 \mathrm{~m}$ at the ice-type boundaries.

\section{Discussion}

In this section we first focus on the comparison between the retrievals from different retracker thresholds. These results are then discussed in the context of the total error budget of the CS-2 freeboard and thickness retrieval where sources of uncertainty are separated into random and systematic uncertainties.

\subsection{Differences between the retrievals of different thresholds}

The comparison of the regional distribution of the CS-2 freeboard map from April 2011 with ASCAT backscatter data 


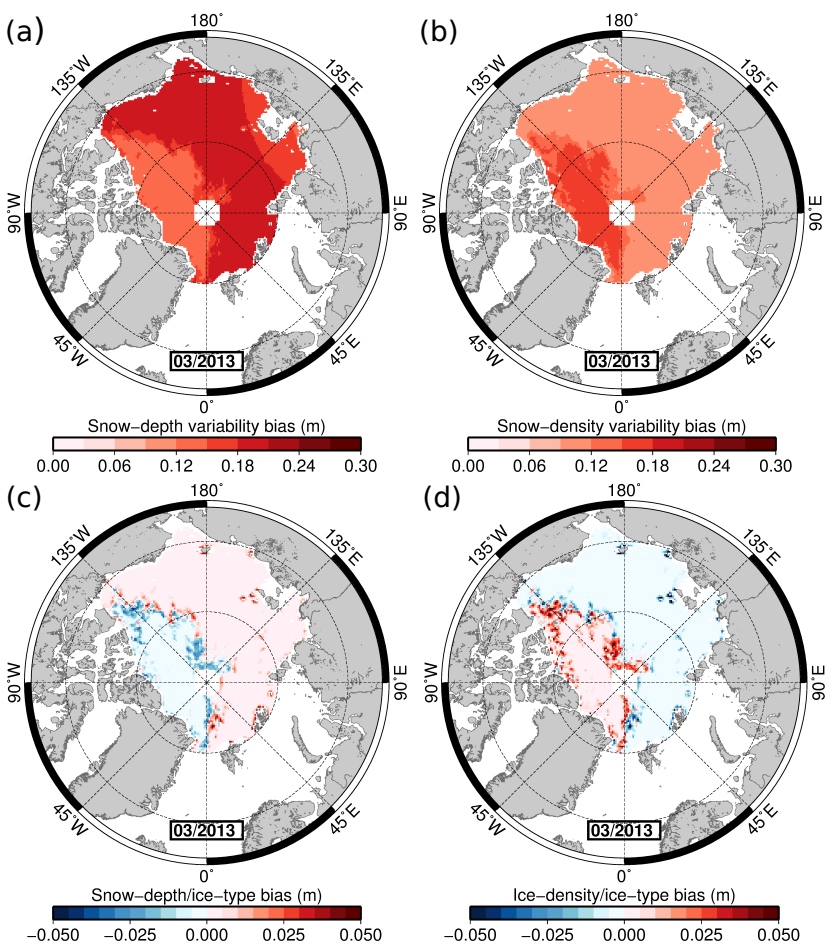

Figure 13. Contribution to the sea-ice thickness bias originating from (a) snow-depth variability, (b) snow-density variability and ice-type-induced uncertainties of (c) snow depth and (d) ice density.

shows similar geographical features. Since MYI is usually associated with higher ASCAT backscatter, both backscatter and freeboard should correlate. Local features, like a small area of potentially MYI in the East Siberian Sea, are visible (red dashed box in Fig. 6a) in both data sets and give confidence that CS-2 is indeed able to capture the actual distribution of sea-ice types.

Considering the freeboard maps in Fig. 9 we find negative freeboard from applying the $80 \%$ threshold for FYI. It needs to be taken into account that the CS-2 freeboard retrievals have not been corrected for the lower wave propagation in the snow layer, which may lift up the freeboard. Therefore a correction term has to be added to $F_{\mathrm{R}}$. Regarding Matzler and Wegmuller (1987), the correction can be applied by reducing the range below the snow-ice interface by the ratio of vacuum speed of light to local speed of light in the snow layer $\left(22 \%\right.$ for a snow density of $\left.300 \mathrm{~kg} \mathrm{~m}^{3}\right)$. If the main scattering horizon is located in the snow layer, either due to the physical properties of the snow or due to the choice of a too-low retracker threshold, the snow propagation correction has to be applied by the fraction of penetration into the snow layer accordingly.

Considering the results of the direct comparison with airborne laser altimetry data, we estimate the mean differences between snow freeboard and the CS-2 freeboard retrievals as the distance that the radar signal propagated through the snow. Hence the mean CS-2 retrievals from the different thresholds are elevated to $0.46 \mathrm{~m}(40 \%), 0.39 \mathrm{~m}(50 \%)$ and $0.22 \mathrm{~m}(80 \%)$. With regard to the snow freeboard from ALS, this indicates a location of the main scattering horizon of $0.16 \mathrm{~m}(40 \%), 0.24 \mathrm{~m}(50 \%)$ and $0.4 \mathrm{~m}(80 \%)$ below the snow surface. Another airborne survey in the framework of Operation IceBridge (OIB) took place in the same area on 15 April (green dotted line in Fig. 7a). The operating airplane carried a snow-depth radar that is able to map the snow depth along the flight track. The data reveal a mean snow depth of $0.31 \mathrm{~m}$ along the track (Kurtz et al., 2012, updated 2014). Furthermore from simultaneous in situ measurements on the ground we additionally know that the mean snow depth exceeded $0.3 \mathrm{~m}$ (Willatt and Haas, 2011). Thus if we assume this value as representative for this area, the $40 \%$ threshold does not track the ice surface. Also the $50 \%$ threshold seems to be too low, which is consistent with the conclusions in Kurtz et al. (2014). On the other hand the $80 \%$ threshold seems to be too high considering the estimated snow depths. We acknowledge that the approach of Kurtz et al. (2014) is significantly different and therefore our approach of using an $80 \%$ threshold can yield different results. We also note that this comparison might be only valid for the multiyear ice region north of Alert in spring. This implies that in the case of the 40 and $50 \%$ threshold we need to apply a geometric correction before converting freeboard to thickness (Eq. 6). This has been done for the AWI CS-2 sea-ice product where a $40 \%$ threshold was used. Nevertheless the spatial and temporal variation of such a geometric correction term is unknown.

The narrow probability density function of the $80 \%$ threshold indicates less variation in the upper part of the leading edge. We can speculate that the shallow probability density function for the 40 and $50 \%$ thresholds (Fig. 8) originate from volume scattering through the snow layer which affects the lower part of the leading edge and leads to increased scattering in the range retrieval.

Considering the spatial differences between the retracker thresholds after gridding indicates a flattened leading edge over MYI and a steep leading edge over FYI. A flat leading edge results in increased range deviations between the retracker thresholds, as can be seen in Fig. 11. This information could be used in the future to obtain an ice-type classification directly from the CS-2 data, similar to the approach of Zygmuntowska et al. (2013). The gradient inside the MYI area in Fig. 11b seems to correlate with the gradient of the radar freeboard retrieval (Fig. 9) and indicates that with increasing radar freeboard the leading edge is flattened, which causes increasing deviations between the retrievals of the different retracker thresholds.

\subsection{Major increase of multiyear ice freeboard in November 2013}

In November 2013 we observe a major increase of radar freeboard in the MYI region north of Greenland and Canada 
compared to previous November data and even March 2013 (Hendricks et al., 2013). This applies to all thresholds, though for the $80 \%$ threshold this increase is less strong and only significantly appears north of Greenland and Canada. This can be considered as unlikely since March represents the end of the winter season and November a period shortly after the beginning of the freeze-up. We can speculate that this is an effect of a higher-than-usual snow load in combination with a limited penetration of the radar pulse into the snow due to non-negligible volume scattering caused by ice lenses and possibly wet snow in the beginning of the freezing season. This further implies that using retracker with $50 \%$ and also a $80 \%$ threshold does not track the ice surface in these conditions, which was assumed by Laxon et al. (2013) and Kurtz et al. (2014). This agrees with results of recent work by Willatt et al. (2010) and Willatt et al. (2011). They show that the CS- 2 range estimates may only partially penetrate into the snow layer; thus a penetration correction would be required. Their findings are based on controlled groundbased $K_{\mathrm{u}}$ band radar experiments and aircraft validation data such as from the CryoSat-2 Validation Experiment (see also Sect. 2.5). Nevertheless the comparison with airborne laser altimetry and the differences between the threshold retrievals give rise to the assumption that the impact of volume scattering and/or surface roughness is reduced using a threshold close to the peak.

Thus we can speculate how to accommodate the spatial and temporal variability of radar penetration in regions or periods where snow conditions can not be considered as cold and dry without significant internal density contrast by ice lenses. In these scenarios where the main scattering horizon is not penetrating the snow load completely, the usage of a low-threshold retracker might be reasonable to track the snow freeboard. On the other hand, in the case of regions where penetration is physically possible, a high-threshold retracker might be the better choice. It would include volume scattering and thus track the ice freeboard. Such a parametrization is hypothetical at the moment and may result in significant biases if the choice of threshold is not correctly timed with the actual snow conditions.

\subsection{The retracking uncertainty in the context of the total uncertainty budget}

The random uncertainties of the radar freeboard are caused by the signal noise and the sea-surface height uncertainty. They can be reduced by averaging inside a $25 \mathrm{~km} \times 25 \mathrm{~km}$ grid cell and decrease with $\sqrt{N}$, where $N$ is the number of measurements to be averaged. Since the CS-2 track density within on month increases with higher latitude towards the North Pole, this results in a latitude-dependent gradient.

The systematic radar freeboard uncertainties originate from the choice of the retracker threshold and both the physical penetration of the radar pulse and the surface roughness. Since these uncertainties cannot be separated with sufficient accuracy, they are treated as a combined contribution. We try to estimate this uncertainty by evaluating the differences between the retrievals of the different thresholds. Between the 40 and the $80 \%$ threshold we find deviations of up to $0.35 \mathrm{~m}$ for MYI, whereas for FYI they remain below $0.1 \mathrm{~m}$. This uncertainty can potentially be reduced with the findings from the direct comparisons with laser altimetry where we relate the threshold retrievals to the snow freeboard and estimated snow depths. Considering the mean difference between the 50 and $80 \%$ retrievals, we can roughly estimate an uncertainty of $0.06 \mathrm{~m}(0.12 \mathrm{~m})$ for FYI (MYI). Since this uncertainty has a systematic nature, it can not be reduced with averaging. Therefore it will dominate the total radar freeboard uncertainty since the random uncertainty contribution is below $0.03 \mathrm{~m}$, neglecting the marginal ice zones.

Considering the sea-ice thickness retrieval, one has to separate again between random and systematic uncertainties. The random uncertainties are composed of the random freeboard uncertainty and the variability of ice density. The composited random thickness uncertainty shows the same pattern and features as the corresponding random freeboard uncertainty and basically is increased by a factor of 10 , which is caused by the freeboard-to-thickness conversion.

Due to the usage of auxiliary products (e.g. snow depth, snow and ice densities, ice type) the sea-ice thickness product is affected by several systematic uncertainties. Their impact depends on the one hand on their individual uncertainty and on the partial derivative (Eq. 8) on the other hand. Among the auxiliary data products the snow-depth uncertainty that arises from interannual variabilities dominates. With regard to Fig. 13a the inverse pattern for the snow-depth variability results from multiplication with the partial derivative. The polarity of Fig. 13c and d is caused by the nature of the icetype product. Since a measuring point can be flagged as either FYI or MYI, the induced error can only point in one direction. Since the classification uncertainty that we retrieve from the confidence level is most significant at the boundary between FYI and MYI, we also find the peak values in those regions. The ice-type-induced ice-density uncertainty shows the same features, but with an inverse polarity. To combine these uncertainties it is necessary to introduce covariances, which is beyond the scope of this study. Therefore we only consider the individual contributions of the systematic uncertainties. However, the systematic uncertainties of the auxiliary variables can possibly not be reduced as long as they are used (e.g. W99 climatology, OSI SAF ice-type product). Additionally we have to consider the bias caused by the choice of the retracker threshold in conjunction with the unknown penetration of the radar pulse and the surface roughness. Due to the freeboard-to-thickness conversion it is increased by a factor of approximately 10 . This results in systematic uncertainties of $0.6 \mathrm{~m}(1.2 \mathrm{~m})$ for FYI (MYI). Like for the freeboard retrieval this bias will dominate the total uncertainty.

However we do acknowledge that the assumption of uncorrelated random uncertainties and thus the reduction by 
averaging might be an insufficient description of certain factors. For example the uncertainty of sea-surface anomaly can only be reduced by gridding if enough lead detections exist. If none are available within one grid cell, the uncertainty contribution due to the lack of leads would be constant for all CS-2 data points and not reduced by gridding. Also temporal variations within 1 month are not included in these considerations, which might be significant during freeze-up and summer melt and result in visible orbit patterns in the monthly means. The temporal and spatial covariances between uncertainty contributions of freeboard and thickness retrievals are only weakly constrained by observations, mainly in Arctic spring, and thus we have limited our uncertainty estimation to a first-order level where we assume correlation (systematic uncertainties) or no correlation (random uncertainties).

\section{Conclusions}

In this study we calculate CryoSat-2 radar freeboard retrievals with consistent uncertainty estimates in spring/autumn 2013, applying three different thresholds for a threshold first-maximum retracker algorithm. The choice of the thresholds is based on current approaches by different scientific groups for CryoSat-2 data processing on Arctic sea ice. In general the application of all thresholds gives confidence that the freeboard retrieval represents the geographyical distribution of sea-ice types. This is shown by direct comparisons with airborne laser altimetry on the local scale as well as with ASCAT backscatter data at basin scale.

Considering first-year ice (multiyear ice) in March 2013 we find mean radar freeboard values of $0.121 \mathrm{~m}(0.265 \mathrm{~m})$ for the $40 \%$ threshold, $0.086 \mathrm{~m}(0.203 \mathrm{~m})$ for the $50 \%$ threshold and $0.024 \mathrm{~m}(0.092 \mathrm{~m})$ for the $80 \%$ threshold. The comparison between the freeboard retrievals from different thresholds and airborne laser altimetry indicates that the 40 and $50 \%$ thresholds are tracking above ice surface, while the $80 \%$ threshold tracks below the ice surface. However, the freeboard maps show that the choice of retracker thresholds does have a significant impact on magnitudes of sea-ice freeboard and thickness estimates, but that the spatial distributions of these parameters are less affected. Analysing the differences between the freeboard retrievals of different thresholds, we find that the leading edge for MYI is less steep compared to the leading edge of FYI. With extraction of this information directly from the CryoSat-2 data the usage of an auxiliary ice-type product would be redundant and could therefore reduce the uncertainties.

Our uncertainty estimates of the gridded data show values up to $0.03 \mathrm{~m}$ for random freeboard uncertainties, neglecting the marginal ice zones. The main driver of their geographical pattern is the density of CryoSat-2 ground tracks, which causes a latitude-dependent gradient. In addition systematic uncertainties of roughly $0.06 \mathrm{~m}(0.12 \mathrm{~m})$ for FYI (MYI) arise from the choice of the retracker and the unknown penetra- tion of the radar pulse into the snow layer. Considering the freeboard-to-thickness conversion we have estimated the resulting uncertainties for the thickness product and find a similar distribution for the random thickness uncertainties, multiplied by a factor of 10 . Due to the usage of auxiliary products (e.g. snow depth, ice and snow densities and ice type) systematic uncertainties in the range between 0.01 and $0.2 \mathrm{~m}$ from each of this variables have to be taken into account. However, the estimated systematic uncertainty of roughly $0.6 \mathrm{~m}(1.2 \mathrm{~m})$ for FYI (MYI) due the choice of the retracker and the unknown penetration of the radar pulse into the snow layer clearly dominates the current thickness uncertainty budget.

Depending on the threshold, the comparison between March and November 2013 retrievals shows an increase of $0.02-0.15 \mathrm{~m}$ of radar freeboard in the MYI region north of Greenland and Canada from March to November, which is unlikely. It gives rise to the assumption that even by applying an $80 \%$ threshold retracker the radar does not penetrate through the snow layer completely. Therefore we can anticipate a seasonal bias in the CryoSat-2 freeboard retrieval and higher-level products.

Thus, for the future it would be useful to investigate different thresholds depending on the properties of the snow load, e.g. seasonal or location specific retrackers. To support this there is a strong need for more information and measurements on the spatial and temporal variability of snow properties.

Acknowledgements. The validation measurements in the framework of CryoVEx and PAMARCMIP 2011 campaigns were carried out by the DTU Space and the Alfred Wegener Institute, Helmholtz Centre for Polar and Marine Research, Bremerhaven, Germany. The CryoVEx campaigns are part of ESA's Living Planet Programme. The CryoSat-2 data are provided by the European Space Agency. The work of S. Hendricks and V. Helm was funded by the Federal Ministry of Economics and Technology (Grant 50EE1008). All of this is gratefully acknowledged.

Edited by: J. Stroeve

\section{References}

Alexandrov, V., Sandven, S., Wahlin, J., and Johannessen, O. M.: The relation between sea ice thickness and freeboard in the Arctic, The Cryosphere, 4, 373-380, doi:10.5194/tc-4-373-2010, 2010.

Andersen, O. B.: The DTU10 Gravity field and Mean sea surface, second international symposium of the gravity field of the Earth (IGFS2), Fairbanks, Alaska, 20-22 September 2010, 2010.

Armitage, T. and Davidson, M.: Using the Interferometric Capabilities of the ESA CryoSat-2 Mission to Improve the Accuracy of Sea Ice Freeboard Retrievals, IEEE T. Geosci. Remote, 52, 529536, doi:10.1109/TGRS.2013.2242082, 2014.

Beaven, S. G., Lockhart, G. L., Gogineni, S. P., Hossetnmostafa, A. R., Jezek, K., Gow, A. J., Perovich, D. K., Fung, A. K., and 
Tjuatja, S.: Laboratory measurements of radar backscatter from bare and snow-covered saline ice sheets, Int. J. Remote Sens., 16, 851-876, doi:10.1080/01431169508954448, 1995.

Brodzik, M. J., Billingsley, B., Haran, T., Raup, B., and Savoie, M. H.: EASE-Grid 2.0: Incremental but Significant Improvements for Earth-Gridded Data Sets, ISPRS Int. J. Geo-Inform, 1, 32-45, doi:10.3390/ijgi1010032, 2012.

Comiso, J. C., Parkinson, C. L., Gersten, R., and Stock, L.: Accelerated decline in the Arctic sea ice cover, Geophys. Res. Lett., 35, L01703, doi:10.1029/2007GL031972, 2008.

Connor, L. N., Laxon, S. W., Ridout, A. L., Krabill, W. B., and McAdoo, D. C.: Comparison of Envisat radar and airborne laser altimeter measurements over Arctic sea ice, Remote Sens. Environ., 113, 563-570, doi:10.1016/j.rse.2008.10.015, 2009.

Drinkwater, M. R.: K u band airborne radar altimeter observations of marginal sea ice during the 1984 Marginal Ice Zone Experiment, J. Geophys. Res.-Oceans, 96, 4555-4572, doi:10.1029/90JC01954, 1991.

Eastwood, S.: OSI SAF Sea Ice Product Manual, v3.8 edn., available at: http://osisaf.met.no (last access: 10 January 2014), 2012.

Forsberg, R., Keller, K., and Jacobsen, S.: Airborne lidar measurements for Cryosat validation, in: Geoscience and Remote Sensing Symposium, 2002, IGARSS '02, 2002 IEEE International, 24-28 June, Toronto, Canada, vol. 3, 1756-1758, doi:10.1109/IGARSS.2002.1026244, 2002.

Giles, K. A., Laxon, S. W., and Ridout, A. L.: Circumpolar thinning of Arctic sea ice following the 2007 record ice extent minimum, Geophys. Res. Lett., 35, L22502, doi:10.1029/2008GL035710, 2008.

Helm, V., Humbert, A., and Miller, H.: Elevation and elevation change of Greenland and Antarctica derived from CryoSat2, The Cryosphere Discuss., 8, 1673-1721, doi:10.5194/tcd-81673-2014, 2014.

Hendricks, S., Ricker, R., and Helm, V.: CryoSat-2 Meereisprodukt, http://www.meereisportal.de/cryosat (last access: 10 July 2014), 2013.

Kurtz, N., Studinger, M. S., Harbeck, J., Onana, V., , and Farrell, S.: IceBridge Sea Ice Freeboard, Snow Depth, and Thickness in the Lincoln Sea, Northern Hemisphere, Tech. rep., Boulder, Colorado USA: NASA DAAC at the National Snow and Ice Data Center, 2012, updated 2014.

Kurtz, N. T. and Farrell, S. L.: Large-scale surveys of snow depth on Arctic sea ice from Operation IceBridge, Geophys. Res. Lett., 38, L20505, doi:10.1029/2011GL049216, 2011.

Kurtz, N. T., Farrell, S. L., Studinger, M., Galin, N., Harbeck, J. P., Lindsay, R., Onana, V. D., Panzer, B., and Sonntag, J. G.: Sea ice thickness, freeboard, and snow depth products from Operation IceBridge airborne data, The Cryosphere, 7, 1035-1056, doi:10.5194/tc-7-1035-2013, 2013.

Kurtz, N. T., Galin, N., and Studinger, M.: An improved CryoSat-2 sea ice freeboard retrieval algorithm through the use of waveform fitting, The Cryosphere, 8, 1217-1237, doi:10.5194/tc-8-12172014, 2014.

Kwok, R., Cunningham, G. F., Wensnahan, M., Rigor, I., Zwally, H. J., and Yi, D.: Thinning and volume loss of the Arctic Ocean sea ice cover: 2003-2008, J. Geophys. Res., 114, C07005, doi:10.1029/2009JC005312, 2009.
Laxon, S.: Sea ice altimeter processing scheme at the EODC, Int. J. Remote Sens., 15, 915-924, doi:10.1080/01431169408954124, 1994.

Laxon, S., Peacock, N., and Smith, D.: High interannual variability of sea ice thickness in the Arctic region, Nature, 425, 947-950, 2003.

Laxon, S. W., Giles, K. A., Ridout, A. L., Wingham, D. J., Willatt, R., Cullen, R., Kwok, R., Schweiger, A., Zhang, J., Haas, C., Hendricks, S., Krishfield, R., Kurtz, N., Farrell, S., and Davidson, M.: CryoSat-2 estimates of Arctic sea ice thickness and volume, Geophys. Res. Lett., 40, 732-737, doi:10.1002/grl.50193, 2013.

Matzler, C. and Wegmuller, U.: Dielectric properties of freshwater ice at microwave frequencies, J. Phys. D Appl. Phys., 20, 1623 1630, doi:10.1088/0022-3727/20/12/013, 1987.

Nghiem, S. V., Rigor, I. G., Perovich, D. K., Clemente-Colón, P., Weatherly, J. W., and Neumann, G.: Rapid reduction of Arctic perennial sea ice, Geophys. Res. Lett., 34, L19504, doi:10.1029/2007GL031138, 2007.

Peacock, N. R. and Laxon, S. W.: Sea surface height determination in the Arctic Ocean from ERS altimetry, Journal of Geophysical Research: Oceans, 109, C07001, doi:10.1029/2001JC001026, 2004.

Rothrock, D. A., Yu, Y., and Maykut, G. A.: Thinning of the Arctic sea-ice cover, Geophys. Res. Lett., 26, 3469-3472, doi:10.1029/1999GL010863, 1999.

Stroeve, J., Serreze, M., Holland, M., Kay, J., Malanik, J., and Barrett, A.: The Arctic's rapidly shrinking sea ice cover: a research synthesis, Climatic Change, 110, 1005-1027, doi:10.1007/s10584-011-0101-1, 2012.

Tonboe, R., Andersen, S., and Pedersen, L.: Simulation of the Kuband Radar altimeter sea ice effective scattering surface, IEEE T. Geosci. Remote, 3, 237-240, doi:10.1109/LGRS.2005.862276, 2006.

Wadhams, P., Tucker, W. B., I., Krabill, W. B., Swift, R. N., Comiso, J. C., and Davis, N. R.: Relationship Between Sea Ice Freeboard and Draft in the Arctic Basin, and Implications for Ice Thickness Monitoring, J. Geophys. Res., 97, 20325-20334, doi:10.1029/92JC02014, 1992.

Warren, S. G., Rigor, I. G., Untersteiner, N., Radionov, V. F., Bryazgin, N. N., Aleksandrov, Y. I., and Colony, R.: Snow Depth on Arctic Sea Ice, J. Climate, 12, 1814-1829, doi:10.1175/15200442(1999)012<1814:SDOASI>2.0.CO;2, 1999.

Willatt, R. and Haas, C.: CryoVEx 2011 Alert Sea Ice Ground Team Report, Tech. rep., ESA, 2011.

Willatt, R., Giles, K., Laxon, S., Stone-Drake, L., and Worby, A.: Field Investigations of Ku-Band Radar Penetration Into Snow Cover on Antarctic Sea Ice, IEEE T. Geosci. Remote, 48, 365 -372, doi:10.1109/TGRS.2009.2028237, 2010.

Willatt, R., Laxon, S., Giles, K., Cullen, R., Haas, C., and Helm, V.: Ku-band radar penetration into snow cover on Arctic sea ice using airborne data, Ann. Glaciol., 52, 197-205, 2011.

Wingham, D., Phalippou, L., Mavrocordatos, C., and Wallis, D.: The mean echo and echo cross product from a beamforming interferometric altimeter and their application to elevation measurement, IEEE T. Geosci. Remote, 42, 2305-2323, doi:10.1109/TGRS.2004.834352, 2004.

Wingham, D., Francis, C., Baker, S., Bouzinac, C., Brockley, D., Cullen, R., de Chateau-Thierry, P., Laxon, S., Mallow, U., Mavrocordatos, C., Phalippou, L., Ratier, G., Rey, L., Rostan, F., 
Viau, P., and Wallis, D.: CryoSat: A mission to determine the fluctuations in Earth's land and marine ice fields, Adv. Space Res., 37, 841-871, doi:10.1016/j.asr.2005.07.027, 2006.

Wingham, D. J., Rapley, C. G., and Griffiths, H.: New techniques in satellite altimeter tracking systems, in: Proceedings of the IGARSS Symposium, Zurich, Switzerland, 8-11 Sepember 1986, edited by: Guyenne, T. and Hunt, J., vol. SP-254, European Space Agency, 1339-1344, 1986.
Zygmuntowska, M., Khvorostovsky, K., Helm, V., and Sandven, S.: Waveform classification of airborne synthetic aperture radar altimeter over Arctic sea ice, The Cryosphere, 7, 1315-1324, doi:10.5194/tc-7-1315-2013, 2013. 